\title{
REESCRIBIRSE A SÍ MISMO: ALGUNAS REPETICIONES TEXTUALES EN CERVANTES, GOETHE Y LORCA
}

\author{
Claudio Castro Filho \\ Universidade de Coimbra \\ Coimbra, Portugal \\ castrofilho@uc.pt
}

\section{RESUMEN / ABSTRACT}

El artículo se enfoca en los desplazamientos y repeticiones textuales patentes en las obras de Cervantes, Goethe y García Lorca, analizándolos como procedimiento estético que pone de relieve la identidad autoral. A partir de las consideraciones de Gumbrecht sobre las diversas etapas de la Modernidad, se relaciona la repetición textual con las distintas estrategias, llevadas a cabo por los tres autores en cuestión, de afirmación o problematización del sujeto literario desde la Modernidad temprana hasta las vanguardias. En dicho contexto, Cervantes inaugura la novela moderna cuando cuestiona la veracidad textual. Goethe, por su parte, establece, a través de la repetición, una relación de complicidad con el lector, mediada por una poética de la memoria. Lorca, por último, recurre a la repetición para difuminar los límites entre yo lírico y personaje dramático, añadiendo nuevas capas de complejidad a la problemática del sujeto en la literatura.

Palabras Clave: repetición textual, Modernidad, Cervantes, Goethe, Lorca.

\section{REWRITING THEMSELVES: SOME OCCURRENCES OF TEXTUAL REPETITION IN CERVANTES, GOETHE AND LORCA}

This paper focuses on the displacements and textual repetitions expresed in Cervantes, Goethe and Garcia Lorca, analyzing them as an aesthetic procedure that highlights the author's identity. Based on Gumbrecht's considerations on the various stages of Modernity, the textual repetition is related to the different strategies, carried out by the three authors in question, of affirming or problematizing the literary subject from Early Modernity to the avant-gardes. In this context, Cervantes inaugurates the modern novel when he questions the verity of the 
text. Goethe, on the other hand, establishes, through repetition, a relationship of complicity with the reader, mediated by a poetics of memory. Lorca, finally, uses to repetition to blur the boundaries between lyric and dramatic character, adding new layers of complexity to the problem of the subject in literature.

KEYWORDS: textual repetition, modernity, Cervantes, Goethe, Lorca.

Recepción: 31/08/2018

Aprobación: 30/04/2019

El propósito del presente artículo radica en revisitar algunas de las repeticiones textuales llevadas a cabo por Cervantes en el Quijote para, a partir de ahí, percibir cómo dicho procedimiento de composición discursiva se inserta en autores que vinieron a formar parte del moderno canon europeo. Goethe y García Lorca, en concreto, se presentan como autores directamente vinculados a la matriz cervantina, según comprueban, respectivamente, Michael Nerlich (con respecto a la generación de Goethe) y Soria Olmedo (con relación a Lorca).

Así pues, la hipótesis que aquí se plantea apunta a que la repetición textual -en cualidad de recurso trans o intertextual-, al menos según el modelo cervantino, sirve para reiterar o problematizar la autoridad textual, al tiempo que insufla al texto características de corte generacional que acaban por diseñar itinerarios de modernización literaria. Para indagar sobre tal perspectiva, recurriremos a los planteamientos de Gumbrecht sobre las distintas etapas de modernización de las letras europeas, desde la modernidad temprana hasta las vanguardias.

En este recorrido, la conciencia del yo autoral camina en pie de igualdad con una contradictoria fragmentación del sujeto y los consecuentes procesos de deshumanización que se verifican en el campo artístico. La repetición textual, en este contexto, se corresponde a un nivel discursivo con la problematización de la autoridad textual y la fragmentación literaria.

\section{LA MODERNIDAD TEMPRANA: REPETICIONES Y DESPLAZAMIENTOS DEL TEXTO EN CERVANTES}

En el capítulo cincuenta de la Segunda Parte de Don Quijote de la Mancha, el paje entrega a Teresa Panza una carta que le pone al tanto de la buena ventura de su marido Sancho, a estas alturas convertido en gobernador de la ínsula Barataria. No resulta fácil la lectura de la misiva (no es que allí supiese leer 
cualquiera) y Sanchica, la hija, propone acudir al cura o más bien al bachiller Sansón Carrasco, los dos letrados del pueblo. El mensajero contesta que no hace falta buscar a nadie, que él la puede leer perfectamente. Tras un diálogo que es todo él el construir de la expectación por la lectura de las noticias, he que el narrador, por fin, pone punto final al tema: "Y, así, se la leyó toda, que por quedar ya referida no se pone aquí" (Cervantes 931). La carta de hecho la conocimos en el capítulo 36, pero resulta como mínimo interesante, en este trozo, la economía narrativa del autor, que esquiva la repetición textual y apuesta por la buena salud del lector, cuya memoria tendrá que retroceder catorce capítulos.

La no repetición de la misiva de Sancho Panza a su señora se configura, además, como un recurso narrativo excepcional dentro de la totalidad del Quijote, quizás porque, como sabemos, la Segunda Parte de la novela está permanentemente marcada por la ironía del narrador con respecto a la veracidad textual -aludiendo, en ocasiones, a la versión apócrifa de Avellaneda, que antecede a la publicación de la secuela de Cervantes--. La cuestión del plagio como procedimiento transtextual parejo a la parodia, según observa Gérard Gennete (10), sirve a Cervantes como dispositivo de comicidad que pone de manifiesto la falsificación como juego metaliterario, lo comprueba Alberto Romero Ferrer (273-284). El constante juego irónico con el suceso de la edición apócrifa cuadra asimismo con la metaficcionalidad que, desde una narrativa escéptica respecto a las categorías de lo falso y lo verdadero, fundamenta el Quijote, según analizan cervantistas como, entre otros, Gustavo Bernardo. El narrador, a estas alturas, relata sucesos presuntamente inferidos por Cide Hamete Benengueli, el historiador musulmán que al narrador cervantino le sirve de base metaficticia, es decir, el "autor original del texto, (...) árabe erudito y gran humanista" (Nerlich 145). Al fin y al cabo, la economía textual respecto al episodio de la carta sobresale como artificio literario desde el que la Segunda Parte toma una importante distancia de la Primera, puesto que la autorrepetición constituye una huella autoral del primer Quijote.

La repetición textual constituye una de las estrategias narrativas que cimientan el cariz ostensivo del Quijote, novela cuya fragmentación episódica establece con la lengua una relación a propósito exhaustiva. El carácter antiaristotélico de una narrativa discontinua, heredado de la lógica textual de la Edad Media (la novela caballeresca de la cual el Quijote hace la parodia), borra ciertos límites entre escritura y oralidad y, al tiempo, conlleva lugares de abundancia marcados por la multiplicación del sentido del texto: un mismo texto se repetirá, una y otra vez, pero dotado de nuevos arreglos semánticos, 
capaces de revelar otras capas de significación. Si es cierto que dicha estética de composición, por un lado, reverbera la tradición épica, también es verdad que el mismo proceder señala rasgos de modernidad que cobrarán fuerza en la literatura barroca, sobre todo en lo que Walter Benjamin caracteriza como las "mónadas" del drama trágico, es decir, un principio constructivo recurrente en el materialismo filosófico, pero que igual se manifiesta en la literatura (véase Benjamin, Origem 35-36). La repetición conlleva asimismo la detención, a la cual le

subyace un principio constructivo. Ahí del pensamiento forman parte no sólo el movimiento del pensar, sino ya también su detención. Cuando el pensar se pára, de repente, en una particular constelación que se halle saturada de tensiones, se le produce un shock mediante el cual él se cristaliza como mónada. (Benjamin, Obras 316-317)

Se trata, al fin y al cabo, de un proceso de composición que sí atraviesa todo el Quijote, pero que en la Segunda Parte se desarrolla poco explícitamente. Aun así, en el capítulo 19, recuerda don Quijote "que dura lo que dura la vida: es un lazo que, si una vez le echáis al cuello, se vuelve en el nudo gordiano" (692), aludiendo a la expresión "que sólo se puede cortar, no desatar", procedente de la vida de Alejandro Magno (692, n. 27). La expresión subyacente al texto volverá a la narrativa en el capítulo 60, cuando el mismo Quijote recupera la expresión de Alejandro: "Si nudo gordiano cortó el Magno Alejandro, diciendo «Tanto monta cortar como desatar»". Esta vez, en lugar de la alusión indirecta de la primera ocurrencia, el texto comparece en forma de analogía, a través de la cual Quijote expresa su preocupación por la vida de Dulcinea del Toboso. Los rasgos legibles explicitan por lo tanto el referente, es decir, las palabras del rey de Macedonia convertidas por Antonio de Nebrija en lema de Fernando el Católico (1105, n. 4).

La repetición textual se expresará en el Quijote a través de múltiples facetas, conllevando asimismo variadas funciones textuales, como por ejemplo, crear puentes de sentido entre las dos partes de la novela. Es lo que ocurre cuando en el capítulo 66 de la Segunda Parte, don Quijote cita de memoria los versos de Orlando furioso, de Ariosto, ya referidos en el capítulo 13 de la primera parte: "Nadie las mueva/ que estar no pueda/ con Roldán a prueba" (116, 1055). La repetitiva incorporación de fragmentos literarios -ya sean heredados de la tradición, tomados de préstamo de autores coetáneos o "hurtados" de sus propios escritos- marca el hipertexto cervantino, según aclara Juan Ramón Muñoz Sánchez (12-17), y confiere historicidad al Quijote. Como 
puede apreciarse, la repetición textual funciona en la economía narrativa del Quijote como artificio de discontinuidad: entre idas y venidas de un mismo texto se edifica un laberinto textual marcado por imágenes que plasman el cariz anti-aristotélico de la narración cervantina.

Dicho proceso, en el primer Quijote, queda patente no solo a través de repeticiones textuales que desplazan un trozo narrativo de la misma obra hacia un nuevo contexto semántico, sino que también se manifiesta en una apropiación de referentes y citas que proceden de otras matrices textuales del propio Cervantes. Al parecer, las repeticiones cervantinas, en su conjunto, forman parte de la poética metaficticia y autorreferente que enmarca la conocida ironía del narrador cervantino respecto a la autoridad textual. Se construye una acumulación de capas de sentido, una colección textual que se caracteriza por la inestabilidad de los significados e identidades. Sobre el primer Quijote, el capítulo 33, la "Novela del curioso impertinente", conforma uno de estos lugares fronterizos de la novela; en el caso, la frontera en cuestión dice respecto a los distintos poemas insertos en la novela y que funcionan como detenciones del tiempo ficticio, al dotar la narrativa de nuevos ritmos textuales.

Es de vidrio la mujer, pero no se ha de probar si se puede o no quebrar, porque todo podría ser.

Y es más fácil el quebrarse, y no es cordura ponerse a peligro de romperse lo que no puede soldarse.

Y en esta opinión estén todos, y en razón la fundo: que si hay Dánaes en el mundo, hay pluvias de oro también. (337-338)

El sobrepasar o exceder la prosa que conforma, en la novela, lo esencial del lenguaje conlleva así una apertura del texto, un instante de disidencia o excepción de la norma que permite al autor incorporar matrices textuales ajenas al propio Quijote. En este caso, la hipótesis defendida por los cervantistas es la que el poema -que recupera, además, el tema mitológico de Dánae, 
encerrada por su padre Acribio en una torre, pero socorrida por Júpiter, que la convierte en una lluvia de oro- procede de una comedia, hoy desconocida, del propio Cervantes $(338$, n. 43). Vuelve a aludirse a la "Novela del curioso impertinente" en el capítulo 47:

El ventero se llegó al cura y le dio unos papeles, diciéndole que los había hallado en un aforro de la maleta donde se halló la Novela del curioso impertinente, y que pues su dueño no había vuelto más por allí, que se los llevase todos, que pues él no sabía leer, no los quería. El cura se lo agradeció y, abriéndolos luego, vio que al principio de lo escrito decía: Novela de Rinconete y Cortadillo, por donde entendió ser alguna novela y coligió que, pues la del Curioso impertinente había sido buena, que también sería aquélla, pues podría ser fuesen todas de un mismo autor... (485).

La alusión, aquí, es al volumen de las Novelas ejemplares de Cervantes publicado en 1613, pero que ya circulaba desde fechas más tempranas en versión manuscrita $(485$, n. 10). Una vez más, el autor se toma a sí mismo como referente, aludiendo a un texto ajeno al Quijote pero que, una vez incorporado al tejido narrativo, asume un nuevo rol literario, en este caso esfumando las fronteras entre lo real y la ficción. La estrategia de metaficción vuelve todavía más compleja la reflexión cervantina sobre la veracidad textual y el concepto de identidad en el campo literario. Pero además del diálogo con obras suyas más allá del Quijote, también ocurren en la Primera Parte repeticiones textuales intrínsecas a la propia novela, a semejanza de lo que ya observamos respecto a la Segunda Parte.

En el capítulo 49, en concreto, don Quijote destaca, en una de sus pláticas, los versos "de estos que dicen las gentes/ que a sus aventuras van" (507). Ya se conoce el rasgo lector del protagonista, cuya cultura literaria atraviesa toda su performance; el destaque de los versos, en ese sentido, reitera la cualidad de letrado del personaje e indica que la cita apunta hacia un referente externo a la novela. En este caso, todo concuerda con que se trata de una adaptación de dos versos de los Trionfi de Petrarca, ya citados en páginas muy precipitadas de la novela, todavía en el capítulo $9(84$, n. 3; 507, n. 30). Por si fuera poco, don Quijote volverá a citar los mismos versos en el capítulo 16 de la Segunda Parte (662). Lo interesante, aquí, es que en la primera ocurrencia los versos no estén atribuidos a don Quijote, sino al narrador. La autoridad textual otra vez se vuelve compleja, puesto que narrador y personaje comparten un mismo texto: el desplazamiento textual cose un entramado tejido que rechaza las identidades fijas y reitera la ficcionalidad de la obra literaria. 
Opera, por tanto, la lógica textual de la copia que empareja el Quijote y la perspectiva filosófica de Erasmo con respecto a la modernidad temprana. En dicho contexto, la copia funciona como un lugar heurístico o físico, volcado sobre la conservación y la clarividencia de las ideas y, lo que sobresale en la poética cervantina, como lugar de rechazo de lo fijo. La dinámica de repetición textual conlleva entonces la imposibilidad de fijarse una identidad textual y el Quijote se confirma, finalmente, como una especie de palimpsesto desde donde se atraen e incorporan trozos textuales de procedencia diversa.

La modernidad temprana equivale, en cierto modo, al que Hans Ulrich Gumbrecht $(11,109)$ llama "Inicio de la Modernidad", periodo o proceso en la historia de las ideas caracterizado por el nacimiento de la noción de subjetividad, que se hace patente en la figura del autor como máscara, y por una posterior toma de distancia entre la razón y el imaginario. En este contexto, podemos comprender el juego de enmascaramiento del yo cervantino como una primera toma de distancia de la autoimagen del hombre medieval, que se representaba "como parte de una creación divina, cuya verdad o bien estaba más allá de la comprensión humana o, a lo mejor, daba a conocerse por la revelación de Dios" (12).

La creciente toma de conciencia del yo como agente en el campo hermenéutico (es decir, como aquel que interpreta el mundo) implica por tanto un "desplazamiento central rumbo a la modernidad" que se manifiesta en el "hecho del hombre verse a sí mismo ocupando el rol de sujeto productor del conocimiento" (Gumbrecht 12). De ahí que el narrador cervantino maneje trucos de identidad bajo los cuales se expresa un yo siempre provisional. En resumidas cuentas, la repetición del texto funciona en Cervantes como rasgo generacional y, al mismo tiempo, como huella dactilar, según analiza Fernanda Canales (6-21). En este contexto, para nada estamos de acuerdo con Mario Vargas Llosa (XV) cuando dice que don "Quijote no cambia, encarcelado como está en su rígida visión caballeresca del mundo". Todo lo contrario, entendemos al personaje -un loco, no por casualidad-como un yo dinámico, que multiplica sus posibilidades identitarias a la vez que incorpora un tejido plural de voces ajenas a un centro organizador de la conciencia. La repetición textual, a fin de cuentas, permite al autor barajar y confundir las voces de don Quijote y del narrador, el mismo narrador que en un primer momento se nos presenta como una máscara del autor, pero que enseguida asume el punto de vista de un presunto narrador musulmán, "Cide Hamete Benengueli, flor de los historiadores" (1020). 


\section{LA MODERNIDAD EPISTEMOLÓGICA: GOETHE Y LA MEMORIA TEXTUAL}

Este proceso histórico tenderá a agudizarse con el avance de la modernidad hacia el periodo que Gumbrecht clasifica como "Modernidad Epistemológica", donde a la hermenéutica de la modernidad temprana se suma el ascenso de las ciencias humanas. Dicho cambio modernizador, conducente a la Ilustración, genera por doquier el "rol de observador que es incapaz de dejar de observarse al mismo tiempo que observa el mundo" (Gumbrecht 13). Hay que convenir en que, en el campo literario, el tema de la repetición o del desplazamiento textual vuelve a cobrar fuerza, y, como ya hemos observado, el drama trágico del periodo barroco constituirá un importante momento de apertura a tendencias estéticas marcadas por la complejidad del sujeto textual -un sujeto que se hace patente por fragmentos, máscaras, mónadas, repeticiones y desplazamientos de las voces textuales-.

Entre los autores paradigmáticos de la "Modernidad Epistemológica" y que recuperan la poética cervantina del desplazamiento textual está, no por casualidad, Goethe. Para los románticos, ilustrados y neoclásicos germánicos, Cervantes representa, ante todo, un signo de modernidad. Heinrich Heine, por ejemplo, "ve en Cervantes aquél que, al derrumbar la novela de caballería de la Edad Media, cuyos protagonistas eran exclusivamente nobles, ha creado la novela moderna, abriendo camino para el pueblo en el espacio novelesco, sin con ello renunciar al sublime" (Nerlich 135). Michael Nerlich observa que la recepción ideológica, filosófica y estética llevada a cabo por los románticos alemanes con respecto al Quijote repercute directamente en la literatura alemana de aquel entonces. El ensayista destaca, entre las obras donde dicha recepción queda explícita, Los años de aprendizaje de Wilhelm Meister, de Goethe, "concebido en el espíritu irónico de Cervantes" (134). Pero, cuando enfocamos en el tema de los desplazamientos y repeticiones textuales, el mismo Fausto emerge como ejemplo paradigmático:

Ihr bringt mit euch die Bilder froher Tage,

Und manche liebe Schatten steigen auf;

Gleich einer alten, halbverklungnen Sage

Kommt erste Lieb' und Freundschaft mit herauf;

Der Schmerz wird neu, es wiederholt die Klage

Des Lebens labyrinthisch irren Lauf,

Und nennt die Guten, die, um schöne Stunden

Vom Glück getäuscht, vor mir hinweggeschwunden.

(Goethe, Fausto vv. 9-16) 
En la clásica traducción de José Roviralta Borrell, que convierte el poema en prosa, leemos:

Aportáis con vosotras las imágenes de placenteros días, y se alzan
muchas sombras amadas, igual que una añeja leyenda medio olvidada,
resurge con ella el primer amor y la primera amistad; renuévase el
dolor, y el lamento vuelve a seguir el laberíntico y extraviado curso de
la vida, nombrando los bienes queridos que, engañados por la dicha,
en horas risueñas, desaparecieron antes que yo. (Goethe, Fausto 29)

El trozo es la segunda estrofa de la "Dedicatoria" [Zueignung] que antecede a los preludios o prólogos de Fausto. No constaba en el proyecto inicial de la obra, sino que se incorpora al texto ya en los últimos años del siglo XVIII (Goethe, en su diario, registra la escritura del texto el 24 de junio de 1797). El poema, aun así, cuadra perfectamente con el anhelo épico de Goethe respecto a su Fausto, puesto que recupera las estancias rítmicas (marcadas por la octava rima) fijadas en la tradición de la poesía épica por Ariosto, Tasso y Camões (véase Mazzari 27).

Es decir, la lógica episódica, fragmentada o antiaristotélica que cimienta la acción dramática de Fausto en su conjunto se hace patente ya en este poema introductorio, que responde por tanto a la estética de las mónadas observada por Benjamin respecto al drama trágico alemán. Hay indicios, sin embargo, de que el poema de 1797 perfecciona un texto de la década anterior, fechado en 1784 y que debería formar parte del libro Geheimnisse [Los secretos] (cf. Citati 479). Es decir, Fausto, al igual que Don Quijote de la Mancha, se configura como una obra palimpsesto, capaz de incorporar textos ajenos a su corpus y que allí se resignifican en un nuevo contexto semántico.

No son pocas las ocurrencias de repeticiones típicamente cervantinas en la literatura de Goethe. Otro ejemplo cristalino se halla en Viaje a Italia, diario de viaje que sin lugar a duda ha sido el granito de arena de Goethe para la construcción de uno de los modernos mitos europeos, el viaje de formación por la antigua Roma y la Magna Grecia (Berthier 191-216). Así pues, llegado el mes de julio de 1787, Goethe se halla en Roma (el diario empieza el 3 de septiembre de 1786), pero en sus cartas a los amigos de Weimar (que no dejan de ser personajes ideales o máscaras con las que Goethe busca la complicidad del lector) el narrador necesita referirse a sucesos ya contados páginas antes, en el mes de abril. He que decide repetir, ipsis litteris, las notas de viaje ya impresas en el mismo libro, explicitando y justificando la repetición con el siguiente informe: 
Para presentar debidamente lo que quiero introducir a continuación, me parece necesario intercalar algunos pasajes del volumen anterior, que en el curso de los acontecimientos podrían haber pasado desapercibidos, porque deseo llamar así de nuevo la atención de los amigos de las ciencias naturales sobre el tema que tanto me importa. (Goethe, Viaje 398-399)

Como se sabe, esa dinámica épica de composición fragmentada de la obra (con idas y venidas que son espaciales, pero a la vez temporales) poco a poco se confirma como técnica moderna de creación artística. Porque de fragmentación se trata: la repetición textual goetheana, cuando devuelve al lector la memoria de fragmentos del relato "que en el curso de los acontecimientos podrían haber pasado desapercibidos", asume la experiencia lectora como apreciación o fruición estética no lineal. La narrativa debe de responder, por ende, a las lagunas cognitivas de una experiencia moderna, marcada por la dispersión de la mirada y por la difusión centrífuga de las ideas literarias. Dentro de esa misma línea procederá, ya en la primera mitad del siglo XX, Federico García Lorca, confeso lector de Cervantes y Goethe.

\section{LAS VANGUARDIAS LITERARIAS: REPETICIÓN TEXTUAL Y ENMASCARAMIENTO DEL YO EN LORCA}

Para Gumbrecht (20), Lorca corresponde a la visión orteguiana del artista de vanguardia al "abandonar la gestalt del hombre y de la humanidad o irse más allá de lo humano", pendiendo hacia "lo que el hombre y la humanidad experimentan como formas y contenidos específicos de su propia mirada del mundo". Esa mirada deshumanizadora del arte conllevará por lo tanto la desacralización (por no decir la deconstrucción) de las categorías subjetivas. La crisis de la subjetividad impulsada o potenciada desde las vanguardias, según observa Eliane Robert Moraes, conllevará, como síntoma literario, un yo que está, de ahora en adelante, puesto en tela de juicio. Según Moraes, dicho proceso se consolida en la literatura europea en un itinerario que empieza en Lautréamont -un maestro del plagio, según Genette (10)- y se concluye en Bataille. Podríamos añadir, si nos atuviésemos al canon francófono, la ruptura con la dicotomía entre forma y sentido que proponen autores como Apollinaire y Mallarmé, creadores que, según Umberto Eco $(14,75)$, proporcionaron a la literatura nuevos grados de apertura artística al disolver la forma y ampliar 
el campo hermenéutico del texto. Así pues, la repetición textual se afirma en las vanguardias como un análogo literario del collage en las artes visuales.

No obstante, interesa aquí tejer una comparativa concreta entre autores que se insertan en una genética cervantina y que, por consiguiente, utilizan de la repetición como procedimiento discursivo que releva lo moderno y problematiza la autoridad textual. Muchos serían los itinerarios posibles, pero la Generación del 27 interesa por lidiar con esta genealogía cuando propaga un ideario explícitamente vinculado con los siglos de oro y con el romanticismo centroeuropeo (véase Soria Olmedo). Federico García Lorca sobresale en las vanguardias literarias españolas por los múltiples recursos de estilización de la voz poética y del personaje dramático (buscando, en cierto modo, construir zonas de intersección entre las dos categorías, la lírica y la dramática) que emplea, entre ellos la repetición textual.

El ejemplo más emblemático de autorreferencialidad y apropiación de un escrito ajeno a la columna vertebral del texto en Lorca se halla, no por casualidad, en una de sus obras más vanguardistas: la pieza teatral Asi que pasen cinco años, fechada en 1931 (primera versión) y 1936 (segunda versión). En las páginas finales del acto primero, el Amigo segundo entona, y lo repite más dos veces, los versos de la canción:

Yo vuelvo por mis alas.

¡Dejadme volver!

¿Quiero morirme siendo amanecer!

Yo vuelvo por mis alas.

¡Dejadme retornar!

Quiero morirme siendo manantial.

Quiero morirme fuera de la mar.

(García Lorca, OC I 220-221)

La canción del Amigo es, en realidad, el poema "El regreso", que integra el libro Suites, de 1921. Es decir, más de una década después, Lorca revisita un 
muy temprano texto suyo y lo recontextualiza en nuevas bases literarias: el yo lírico se convierte en personaje dramático; la suite, en interludio musical. La recuperación del texto de los años veinte, que se incorpora al tejido dramático de la obra de los treinta, transforma la voz poética y enmascara, a la manera cervantina, la veracidad del texto y la identidad autoral. No sería exagerado decir que toda la obra de Lorca se edifica sobre el problema de la veracidad del yo. Según el análisis de Juan Carlos Rodríguez, el teatro de Lorca (se refiere con precisión a sus llamadas "comedias irrepresentables", de las que forma parte Así que pasen cinco años) pone en escena

la producción (falsa) del sujeto. Falsa en tanto que a la vez real: la clave de la ideología y su inconsciente. (...) Es decir, el sujeto no posee título alguno (...) salvo su máscara de sujeto/autor (supuesto poseedor de sentido), que no es sino el lugar donde se borran todas las máscaras: el lugar donde el sentido no se restablece sino que se busca. (Rodríguez 95)

El desplazamiento y la repetición textuales son algunos de los síntomas o signos de esa imposibilidad de aprehensión del sujeto y, consiguientemente, del sentido del texto como categoría escurridiza, es decir, el sentido como búsqueda, como puro devenir. Al fin y al cabo, el yo lorquiano se expresa bajo la capa del misterio: las mismas palabras sirven, en 1921, al yo lírico (ese despliegue del yo autoral) y, en los años treinta, al personaje dramático (marcado por la ficcionalidad intrínseca al yo teatral).

\section{CONSIDERACIONES FINALES}

Caminando hacia una conclusión, observamos que la autorreferencia impresa en la copia, la repetición y la resignificación textual constituyen un método que añade a la obra literaria moderna la cualidad de receptáculo o repositorio de ideas y variantes semánticas. Dicho proceso, en los ejemplos aquí analizados, está fundamentalmente involucrado con la experiencia moderna y la construcción y problematización del concepto de sujeto textual.

En Cervantes, el desplazamiento textual conlleva un juego de enmascaramiento del yo que expresa el hito histórico de los descubrimientos de Copérnico: la centralidad de Dios en cuanto demiurgo productor del sentido está puesta en causa por un sujeto literario que demuestra una 
capacidad autónoma de interpretar el mundo. El yo cervantino, en sus múltiples facetas y capas, aparenta estar ya en posesión de sus facultades hermenéuticas. En definitiva, las repeticiones y desplazamientos textuales llevados a cabo por Cervantes cimientan una escritura escéptica, donde las categorías de veracidad o falsedad textual están puestas en tela de juicio, puesto que no son clarividentes los límites que distinguen las múltiples capas de ficción que atraviesan la novela.

En Goethe, por su parte, este proceso se convertirá en un agravamiento de la relación dialéctica entre el yo y el mundo, lo que es lo propio y lo que es lo ajeno: el sujeto se observa a sí mismo igual que al mundo y, en la literatura, dicho fenómeno se expresa en esa proyección del yo sobre el otro que los desplazamientos textuales de Fausto, por ejemplo, revelan. Sin embargo, el yo autoral (más allá del narrador en cuanto categoría literaria) camina hacia el otro, una otredad idealmente plasmada en la figura del lector, aquel que requiere una fragmentación del texto porque igual de fragmentada es su experiencia vital. De ahí las repeticiones de relatos en Viaje a Italia, asumiéndose la fugacidad de la memoria como parte de la experiencia, o mejor dicho, como parte del viaje.

Lorca, por último, regresa a la mirada barroca del yo y del mundo no para recuperarla tal cual, sino para apropiarse de una tradición, revisándola mediante el adviento de la crisis del sujeto. Recupera una dinámica textual que deconstruye el yo mientras lo desplaza: de lo lírico a lo dramático, de lo subjetivo a lo deshumanizado. El desborde de los límites entre personaje y yo lírico, propiciado por el entrelazamiento de textos poéticos y dramáticos, difumina, en Lorca, la noción de identidad literaria.

Ya sea como artificio o como procedimiento de composición, la repetición textual atraviesa la historia de la literatura desde la Antigüedad. Las tragedias de Eurípides son un testigo casi hiperbólico de ello. Los cinco versos finales del coro de Medea, por ejemplo, se repiten ipsis litteris en cuatro piezas suyas más: Alceste, Andrómaca, Bacantes y Elena (véase Eurípides 290, n. 110). Sin embargo, la genealogía literaria moderna - de la que Cervantes, Goethe y Lorca son paradigmas- pone de relieve, con la repetición, la paulatina construcción de una consciencia literaria que forja una identidad ficticia al problematizar la autoridad textual. Al fin y al cabo, repetirse a sí mismo es esparcir el yo por un lugar donde la abundancia textual es, por excelencia, literatura moderna. 


\section{BIBLIOGRAFÍA}

Benjamin, Walter. Obras Completas I. Trad. Alfredo Brotons. Madrid: Abada, 2007.

Origem do drama barroco alemão. Trad. João Barrento. Belo Horizonte: Autêntica, 2011.

Bernardo, Gustavo. Verdades quixotescas: ensaios sobre a filosofia de Dom Quixote da Mancha. São Paulo: Annablume, 2006.

Berthier, Philippe. "A viagem à Itália”. O olhar de Orfeu: os mitos literários do Ocidente. Org. Bernadette Bricout. Trad. Lelita Oliveira Benoit. São Paulo: Companhia das Letras, 2003. 191-216.

Cervantes, Miguel de. Don Quijote de la Mancha. Edición de Francisco Rico. Madrid: Real Academia Española, 2004.

Canales, Fernanda. "Una conversación con Miguel de Cervantes: repetición y singularidad", Croquis, núm. 193 (2018): 6-21.

Citati, Pietro. Goethe. Trad. Rosa Freire D’Aguiar. São Paulo: Companhia das Letras, 1996.

Eco, Umberto. Obra abierta: forma e indeterminación en el arte contemporáneo. Trad. Roser Berdagué. Barcelona: Planeta-Agostini, 1992.

Eurípides. Medeia. Tradução e notas de Maria Helena da Rocha Pereira. Lisboa: Fundação Calouste Gulbenkian, 2005.

García Lorca, Federico. Obras completas, 4 vols. Edición de Miguel García-Posada. Barcelona: Galaxia Gutenberg, 1997.

Genette, Gérard. Palimpsestos: la literatura en segundo grado. Trad. Celia Fernández Prieto. Madrid: Taurus, 1989.

Goethe, Johann Wolfgang von. Fausto - uma tragédia, 2 vols. Edição bilíngue. Trad. Jenny Klabin Segall. São Paulo: 34, 2007.

Fausto. Trad. José Roviralta Borrell. Madrid: Alianza, 2014.

Viaje a Italia. Trad. Manuel Scholz Rich. Barcelona: Zeta, 2017.

Gumbrecht, Hans Ulrich. Modernização dos sentidos. Trad. Lawrence Flores Pereira. São Paulo: 34, 1998.

Mazzari, Marcus Vinicius. Apresentação, comentários e notas. En Goethe, Johann Wolfgang von. Fausto - uma tragédia, 2 vols. Edição bilíngue. Trad. Jenny Klabin Segall. São Paulo: 34, 2007.

Moraes, Eliane Robert. O corpo impossível: a decomposição da figura humana de Lautréamont a Bataille. São Paulo: Iluminuras, 2002.

Muñoz Sánchez, Juan Ramón. La reescritura en Cervantes: el tema del amor. Madrid: Universidad Autónoma de Madrid, 2009.

Nerlich, Michael. "Dom Quixote ou o combate em torno de um mito". O olhar de Orfeu: os mitos literários do Ocidente. Org. Bernadette Bricout. Trad. Lelita Oliveira Benoit. São Paulo: Companhia das Letras, 2003. 122-147.

Rodríguez, Juan Carlos. Lorca y el sentido: un inconsciente para una Historia. Madrid: Akal, 1994. 
Romero Ferrer, Alberto. "Sobre la falsificación literaria, el plagio y otras atrocidades de la filología (en torno al Buscapié de Cervantes)". Marginados, disidentes y olvidados en la historia. Ed. Santiago Moreno Tello y José Joaquín Rodríguez. Cádiz: Universidad de Cádiz, 2009. 273-284.

Soria Olmedo, Andrés. La Generación del 27: ¿aquel momento ya es una leyenda? Madrid/ Sevilla: SECC/Junta de Andalucía/Residencia de Estudiantes, 2009.

Vargas Llosa, Mario. "Una novela para el siglo XXI". En Miguel de Cervantes. Don Quijote de la Mancha. Edición de Francisco Rico. Madrid: Real Academia Española, 2004. XIII-XXVIII. 